\title{
Wnt3a inhibits proliferation but promotes melanogenesis of melan-a cells
}

\author{
HAIYING GUO, KE YANG, FANG DENG, YIZHAN XING, YUHONG LI, XIAOHUA LIAN and TIAN YANG \\ Department of Cell Biology, Third Military Medical University, Chongqing 400038, P.R. China
}

Received March 9, 2012; Accepted May 14, 2012

DOI: $10.3892 / \mathrm{ijmm} .2012 .1028$

\begin{abstract}
Melanocytes are pigment-producing cells responsible for coloration of skin and hair. Although the importance of Wnt3a in melanocyte development has been well recognized, the role of Wnt3a in mature melanocytes has not been elucidated. This study was conducted to further explore the effects of Wnt3a on melanocyte proliferation and melanogenesis, and to elucidate the possible mechanisms involved. We infected melan-a cells with AdWnt3a to serve as the production source of the Wnt3a protein. MTT assay, 5-bromodeoxyuridine incorporation assay and flow cytometric analysis showed that Wnt3a inhibited the proliferation of melan-a cells and this was associated with decrease of cells in the $\mathrm{S}$ phase and increase of cells in the $G_{1}$ phase. Melanin content and tyrosinase activity assay revealed that Wnt3a significantly promoted melanogenesis of melan-a cells. Furthermore, western blot analysis showed that Wnt3a upregulated the expression of microphthalmia-associated transcription factor and its downstream target genes, tyrosinase and tyrosinase-related protein 1 in melan-a cells. Collectively, our results suggest that Wnt3a plays an important role in melanocyte homeostasis.
\end{abstract}

\section{Introduction}

Melanocytes play pivotal roles in skin and hair pigmentation by producing melanin $(1,2)$. They originate from neural crestderived melanoblasts and migrate into the epidermis and hair follicles during embryogenesis $(3,4)$. Melanocytes synthesize melanin in melanosomes and transfer the melanin granules to the adjacent keratinocytes, where melanins are accumulated to generate pigmented skin or hairs. High melanin content

Correspondence to: Professor Tian Yang, Department of Cell Biology, Third Military Medical University, Shapingba, Chongqing 400038, P.R. China

E-mail: tiany@163.net

Abbreviations: BrdU, 5-bromodeoxyuridine; Fzd, Frizzled; LRP, low-density lipoprotein-related protein; Ad, adenovirus; MITF, microphthalmia-associated transcription factor; TRP2, tyrosinaserelated protein 2; TRP1, tyrosinase-related protein 1

Key words: Wnt3a, Wnt/ $\beta$-catenin signaling, melanocyte, proliferation, melanogenesis protects the skin from harmful ultraviolet rays owing to the ability to absorb UV radiation and quench the UV-induced intracellular free radicals $(1,5,6)$. Defects in or a lack of melanocytes can lead to pigment disorders, such as piebaldism, albinism, vitiligo, and hair graying (7-9).

Wnts are a large family of secreted glycoproteins that act as ligands to activate receptor-mediated signaling pathways that play important roles in cell fate, proliferation, differentiation and migration (10-13). Wnt signaling can be divided into at least two distinct pathways: canonical Wnt/ $\beta$-catenin signaling and noncanonical signaling. In the best characterized canonical pathway, Wnt ligands bind to seven-pass transmembrane receptors of the Frizzled (Fzd) family and co-receptors, low density lipoprotein-related protein (LRP) 5 and 6 , leading to the inhibition of the APC/Axin/CK1/GSK3b destruction complex and stabilization and translocation of $\beta$-catenin to the nucleus where it interacts with $\mathrm{TCF} / \mathrm{Lef}$ family transcription factors to regulate the transcription of target genes $(11,12)$. Contrary to canonical Wnt signaling, noncanonical Wnt signaling is transduced independently of $\beta$-catenin. Noncanonical Wnt signaling pathways are diverse and less well characterized, and have been termed the Wnt/calcium, Wnt/JNK pathway and Wnt/planar cell polarity pathway (PCP) (11).

Previous studies revealed that Wnt signaling plays a critical role in melanocyte development, specifically Wnt1 and Wnt3a. Wnt1 and Wnt3a promote the development of neural crest cells into pigment cells $(14,15)$. Neural crest cells depleted of these two proteins become neuronal rather than melanocytes (14). Wnt1 acts on melanoblasts to increase melanocyte numbers, while Wnt3a and $\beta$-catenin can specify neural crest cells to become melanocytes $(16,17)$. Mutant mice deficient in Wnt1 and Wnt3a are almost completely devoid of pigment cells (18). Furthermore, Wnt3a acts on melanoblasts to maintain microphthalmia-associated transcription factor (MITF) expression and promote melanoblasts to differentiate to become melanocytes (16). In humans, high levels of DKK1 (an inhibitor of the canonical Wnt signaling pathway) inhibits melanocyte growth, pigmentation and induces a less pigmented skin on the palms $(19,20)$.

Although the importance of Wnt3a in melanocyte development has been well recognized, the role of Wnt3a in mature melanocytes remains undetermined. To address this issue, adenoviral gene delivery of $\mathrm{Wnt} 3 \mathrm{a}$ was adopted to investigate the effects of Wnt3a on melan-a melanocyte proliferation and melanogenesis, and to elucidate the possible mechanisms involved. 


\section{Materials and methods}

Cell culture. An immortal line of melanocytes, melan-a, were a kind gift of Dr D.C. Bennett (21). The cells were cultured in RPMI-1640 medium supplemented with 10\% FBS (Gibco, USA), 2 mM L-glutamine, $200 \mathrm{nM}$ 12-o-tetradecanoyl phorbol13 -acetate (Sigma, USA), $100 \mathrm{IU} / \mathrm{ml}$ penicillin, $50 \mu \mathrm{g} / \mathrm{ml}$ streptomycin, and grown in a humidified atmosphere containing $10 \% \mathrm{CO}_{2}$ in air at $37^{\circ} \mathrm{C}$.

Adenovirus (Ad) amplification and infection. The adenoviruses expressing green fluorescent protein (AdGFP), Wnt3a protein (AdWnt3a, also expressing GFP), and SimMITF (AdSimMITF, a small interfering RNA of MITF mediated by adenovirus, also expressing RFP) were kindly provided by $\mathrm{Dr}$ T.C. He (Chicago University). The adenoviruses were propagated and purified as previously described (22). Briefly, the adenoviruses were propagated in HEK293 cells, which were collected upon detection of viral cytopathic effect-successful infections were verified by observable GFP incorporation. Cell pellets were resuspended in PBS and lysed by four freezethaw-vortex cycles. After being purified by cesium chloride (Amresco, USA) density gradient centrifugation, adenoviruses were dialyzed into storage buffer, then their titers were determined and diluted with storage buffer to the ultimate titer of $10^{8}$ plaque-forming unit (PFU)/ml. For infection, melan-a cells were plated onto 6- or 24-well plates at a density of $2 \times 10^{4}$ cells/ $\mathrm{cm}^{2}$ in the growth medium for $12 \mathrm{~h}$, the cells were then grown in medium supplemented with adenoviruses for $72 \mathrm{~h}$.

Isolation of total-RNA and RT-PCR. Total cellular RNA was isolated at the indicated time-points using TRIzol reagent (Invitrogen, USA). Single-stranded cDNA was synthesized by using ReverTra Ace reverse transcriptase (Toyobo, Japan) and oligo(dt) primers according to the manufacturer's protocol. Semi-quantitative PCR was performed using primers for Fzd1-10, LRP5, LRP6, MITF, tyrosinase-related protein (TRP)1, TRP2, tyrosinase (Table I lists the primer sequences and amplicon size). PCR reaction was performed by using a touchdown protocol previously described (23). Briefly, touchdown PCR was performed with the following program: 1 cycle at $94^{\circ} \mathrm{C}$ for $2 \mathrm{~min}, 12$ cycles at $92^{\circ} \mathrm{C}$ for $20 \mathrm{sec}, 68^{\circ} \mathrm{C}$ for $30 \mathrm{sec}$, and $70^{\circ} \mathrm{C}$ for $45 \mathrm{sec}$ with a decrease of one degree per cycle, and 25 cycles at $92^{\circ} \mathrm{C}$ for $20 \mathrm{sec}, 55^{\circ} \mathrm{C}$ for $30 \mathrm{sec}$, and $70^{\circ} \mathrm{C}$ for $45 \mathrm{sec}$. PCR products were analyzed by gel electrophoresis and stained with ethidium bromide.

TOP/FOP-flash luciferase reporter assay. Melan-a cells were seeded onto 24-well plates overnight and subsequently infected with AdWnt3a or AdGFP. After $12 \mathrm{~h}$, the cells were transfected with TOP/FOP-flash luciferase reporter plasmid. For each well, $3 \mu \mathrm{g}$ TOP- or FOP-Flash Firefly Luciferase reporter plasmid, which contain several TCF4-binding elements (TOP) or mutant sequences (FOP), respectively, were transfected together with $0.03 \mu \mathrm{g}$ phRG-TK Renilla Luciferase standard plasmid (Promega, USA). The transfection reagent, Lipofectamine 2000 (Invitrogen), was used according to the standard protocol. Cell lysates were harvested $24 \mathrm{~h}$ after transfection and the Dual-Luciferase Reporter Assay System (E1910; Promega) was used to detect luciferase activity
Table I. Primer sequences for RT-PCR analysis.

\begin{tabular}{|c|c|c|}
\hline Primer & Sequence $\left(5^{\prime} \rightarrow 3^{\prime}\right)$ & GenBank ID \\
\hline LRP5 & $\begin{array}{l}\text { F: GGTCACCTGGACTTCGTCAT } \\
\text { R:TCCAGCGTGTAGTGTGAAGC }\end{array}$ & NM_008513.3 \\
\hline LRP6 & $\begin{array}{l}\text { F: ACAGAGCCCTGACATCATCC } \\
\text { R: TGATTTGCGACTGAGTTTGC }\end{array}$ & NM_008514.4 \\
\hline Fzd1 & $\begin{array}{l}\text { F: CAAGGTTTACGGGCTCATGT } \\
\text { R: GTAACAGCCGGACAGGAAAA }\end{array}$ & NM_021457.3 \\
\hline Fzd2 & $\begin{array}{l}\text { F: TTAGCGGCCTGAGAGATGTT } \\
\text { R: CAGGAGAGACGGTTGAGAGC }\end{array}$ & NM_020510.2 \\
\hline Fzd3 & $\begin{array}{l}\text { F: GCTCCAGGAACCTGACTTTG } \\
\text { R: GACACTCCCTGCTTTGCTTC }\end{array}$ & NM_021458.2 \\
\hline Fzd4 & $\begin{array}{l}\text { F: AACCTCGGCTACAACGTGAC } \\
\text { R: TGGCACATAAACCGAACAAA }\end{array}$ & NM_008055.4 \\
\hline Fzd5 & $\begin{array}{l}\text { F: AGGCATCCCGATTTTCTTTT } \\
\text { R: TGAGCGAGGGCAGAGTATTT }\end{array}$ & NM_022721.3 \\
\hline Fzd6 & $\begin{array}{l}\text { F: TCCGACGCTTGAAGAAAACT } \\
\text { R: CAACCCCAGGTCCTCAAGTA }\end{array}$ & \\
\hline Fzd7 & $\begin{array}{l}\text { F: ATCATCTTCCTGTCGGGTTG } \\
\text { R: AAGCACCATGAAGAGGATGG }\end{array}$ & NM_008057.3 \\
\hline Fzd8 & $\begin{array}{l}\text { F: CTGTTCCGAATCCGTTCAGT } \\
\text { R: CGGTTGTGCTGCTCATAGAA }\end{array}$ & NM_008058.2 \\
\hline Fzd9 & $\begin{array}{l}\text { F: TTATGGTTGCTCCCTCCTTG } \\
\text { R: CACTCCCTGCATGAGACAGA }\end{array}$ & NM_010246.1 \\
\hline Fzd10 & $\begin{array}{l}\text { F: TCCTCACCCTCACTTGGTTC } \\
\text { R: GCTGCCCACATAACACACAC }\end{array}$ & NM_175284.3 \\
\hline
\end{tabular}

F, forward; R, reverse.

according to the manufacturer's protocol. The experiments were performed in triplicate.

Cytometry and MTT assays. To study the effect of Wnt3a on melan-a proliferation, $2 \times 10^{4}$ melan-a cells were plated onto 24-well plates overnight and grown in culture medium supplemented with AdWnt3a at various doses $(1,2,3 \mu 1)$ or $2 \mu \mathrm{l}$ AdGFP as the vehicle control. After $72 \mathrm{~h}$, the cells were detached with trypsin and counted in a hemocytometer. For the MTT assay, melan-a cells were plated onto 96-well plates and treated with AdWnt3a at various doses $(0.2,0.5,0.8 \mu \mathrm{l})$ or $0.5 \mu \mathrm{l}$ AdGFP for $72 \mathrm{~h}$. Then MTT (Sigma) was added, and the cells were incubated at $37^{\circ} \mathrm{C}$ for $4 \mathrm{~h}$. The medium was removed and dimethyl sulfoxide (DMSO) was added to dissolve the formazan crystals. The absorbance was then measured at $490 \mathrm{~nm}$ with a common ELISA reader.

5-Bromodeoxyuridine incorporation assay. Melan-a cells were plated onto glass coverslips and were treated with AdWnt3a or AdGFP. After 72 h, 5-bromodeoxyuridine (BrdU, Sigma; stock of $10 \mathrm{mM}$ in PBS) was added at $10 \mu \mathrm{M}$. The cells were then incubated at $37^{\circ} \mathrm{C}$ for $2 \mathrm{~h}$ and fixed in cold acetone for $10 \mathrm{~min}$. After washing three times in PBS, the cells were incubated in $2 \mathrm{M} \mathrm{HCl}$ for $45 \mathrm{~min}$ to denature the DNA and then neutralized 
A

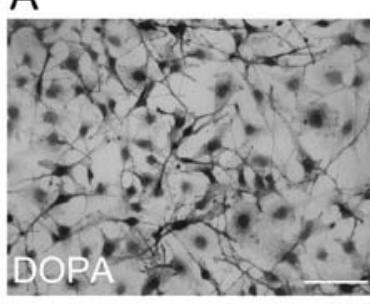

B

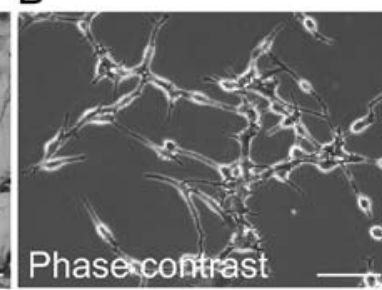

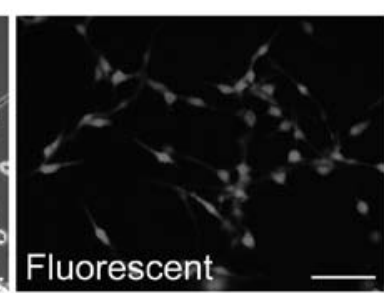

C

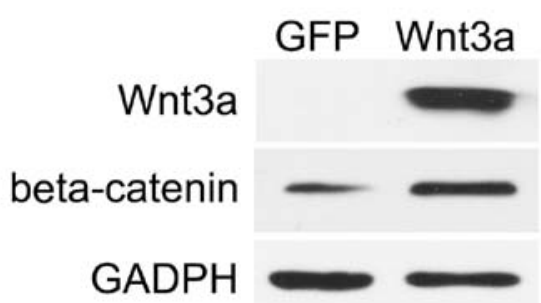

$\mathrm{D}$

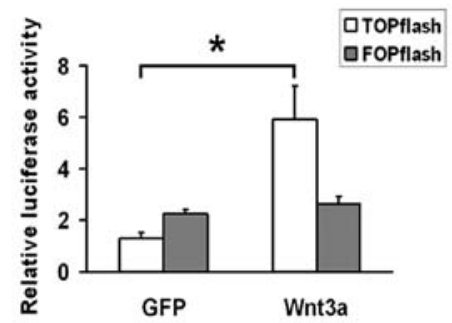

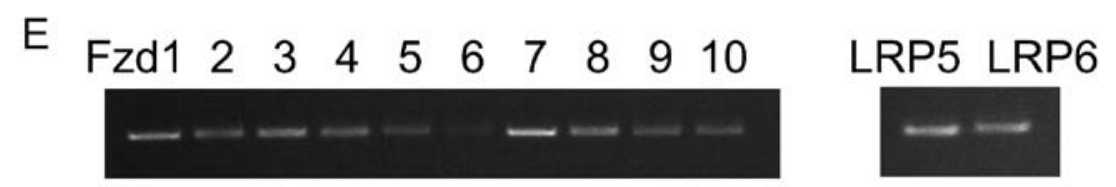

Figure 1. Analysis of Wnt3a activity in melan-a cells after infection with AdWnt3a. (A) DOPA staining of melan-a cells. Melan-a cells were positive for DOPA histochemical staining. (B) AdWnt3a mediated efficient gene transfer in melan-a cells. Since the recombinant adenoviral vector, AdWnt3a, also expresses GFP, expression of GFP was recorded by using fluorescence microscopy $24 \mathrm{~h}$ after infection. (Left, phase contrast images; right, fluorescent images). (C) Western blot analysis of Wnt3a and $\beta$-catenin in melan-a cells after infection with AdWnt3a or AdGFP. (D) Analysis of Wnt/ $\beta$-catenin signaling activity in AdWnt3a-infected cells by luciferase reporter assays. Melan-a cells infected with AdGFP control vector or AdWnt3a were transfected with TOP-flash or the control FOP-flash plasmids. Higher TOP-flash/FOP-flash ratios were found in the AdWnt3a-infected cells. (E) RT-PCR for the expression of receptors of Fzd1 to Fzd10 and LRP5/6 mRNA in melan-a cells. ${ }^{*} \mathrm{P}<0.05$. $\mathrm{n}=3$. Scale bars, $50 \mu \mathrm{m}$.

with $0.1 \mathrm{M} \mathrm{Na}_{2} \mathrm{~B}_{4} \mathrm{O}_{7}(\mathrm{pH} 8.5)$ for $30 \mathrm{~min}$. The detection of BrdU was performed with a mouse anti-BrdU antibody $(1: 100$; Zhongshan, China) at $4^{\circ} \mathrm{C}$ overnight. Then, cells were incubated with goat anti-mouse FITC-conjugated secondary antibody (1:100; Zhongshan) at $37^{\circ} \mathrm{C}$ for $1 \mathrm{~h}$. After washing, the cells were stained with DAPI for $10 \mathrm{~min}$ at room temperature. Six areas/well were randomly selected and counted with an upright microscope BH2 (Olympus, Japan).

Flow cytometric analysis. Melan-a cells were plated onto 6-well plates and treated with $2 \mu \mathrm{l}$ AdWnt3a or $2 \mu \mathrm{l}$ AdGFP for $72 \mathrm{~h}$. Afterward, cells were dissociated with trypsin, washed in PBS, and fixed in $1 \mathrm{ml}$ of $70 \%$ methanol at $4^{\circ} \mathrm{C}$ for at least $24 \mathrm{~h}$. The fixed cells were washed twice in PBS, treated with $100 \mu \mathrm{g} / \mathrm{ml}$ RNase and $50 \mu \mathrm{g} / \mathrm{ml}$ propidium iodide (PI) in PBS for $30 \mathrm{~min}$ at $37^{\circ} \mathrm{C}$, and the cell cycle was detected with a flow cytometer. All proliferation assays were performed in triplicate.

Tyrosinase enzymatic assay. Tyrosinase activity assays were performed according to the method previously reported (24). Melan-a cells in 6-well plates were infected with AdWnt3a or AdGFP for $72 \mathrm{~h}$, then trypsinized and counted. Cells $\left(1 \times 10^{5}\right)$ were treated with $200 \mu 1$ of $1 \%$ Triton X-100/PBS at $-70^{\circ} \mathrm{C}$ for $30 \mathrm{~min}$ and thawed at $37^{\circ} \mathrm{C}$. Then, the extracts were clarified by centrifugation, $50 \mu \mathrm{l}$ of the supernatant were transferred into 96-well plates and $10 \mu \mathrm{l}$ of $2 \mathrm{mg} / \mathrm{ml}$ L-DOPA (Sigma) were added. After incubation for $2 \mathrm{~h}$ at $37^{\circ} \mathrm{C}$, absorbance was measured at $490 \mathrm{~nm}$. The experiments were performed at least three times.
Western blot analysis. Cells were lysed in RIPA lysis buffer (Beyontime, China), determined by the Enhanced BCAProtein Assay kit (Beyontime) and denatured by boiling. Protein of $80 \mu \mathrm{g}$ per lane was loaded on $10 \%$ SDS-PAGE and then transferred onto a PVDF membrane. Membranes were blocked with $5 \%$ fat-free milk in Tris-buffered saline-Tween-20 (TBST; $20 \mathrm{mM}$ Tris/ $\mathrm{HCl}, \mathrm{pH} 7.6,137 \mathrm{mM} \mathrm{NaCl}, 0.1 \%$ Tween-20) for $2 \mathrm{~h}$, then membranes were probed with rabbit anti-Wnt3a antibody (1:1,000; Abcam, USA), goat anti-TRP1 antibody $(1: 1,000)$, rabbit anti-TRP2 antibody $(1: 1,000)$, goat anti-tyrosinase antibody $(1: 1,000$; Santa Cruz Biotechnology, Inc., USA), and mouse anti-MITF antibody (1:500, Millipore, USA) at $4^{\circ} \mathrm{C}$ overnight. Blots were then incubated with HRP-conjugated secondary antibody. Peroxidase activity on the membrane was visualized on X-ray film by means of the ECL western blotting detection system.

Statistical analysis. Data were presented as means \pm SD for the three independent experiments. Statistical differences were evaluated by the $\mathrm{t}$-test, and $\mathrm{P}<0.05$ was considered to be statistically significant.

\section{Results}

Wnt3a activates Wnt/ $\beta$-catenin signaling in melan-a cells. To explore the potential role of Wnt3a in mouse mature melanocytes, we used a mouse melanocyte cell line, melan-a (21), as an in vitro cell model. DOPA staining was used to confirm that the cells were indeed melanocytes (Fig. 1A). RT-PCR 

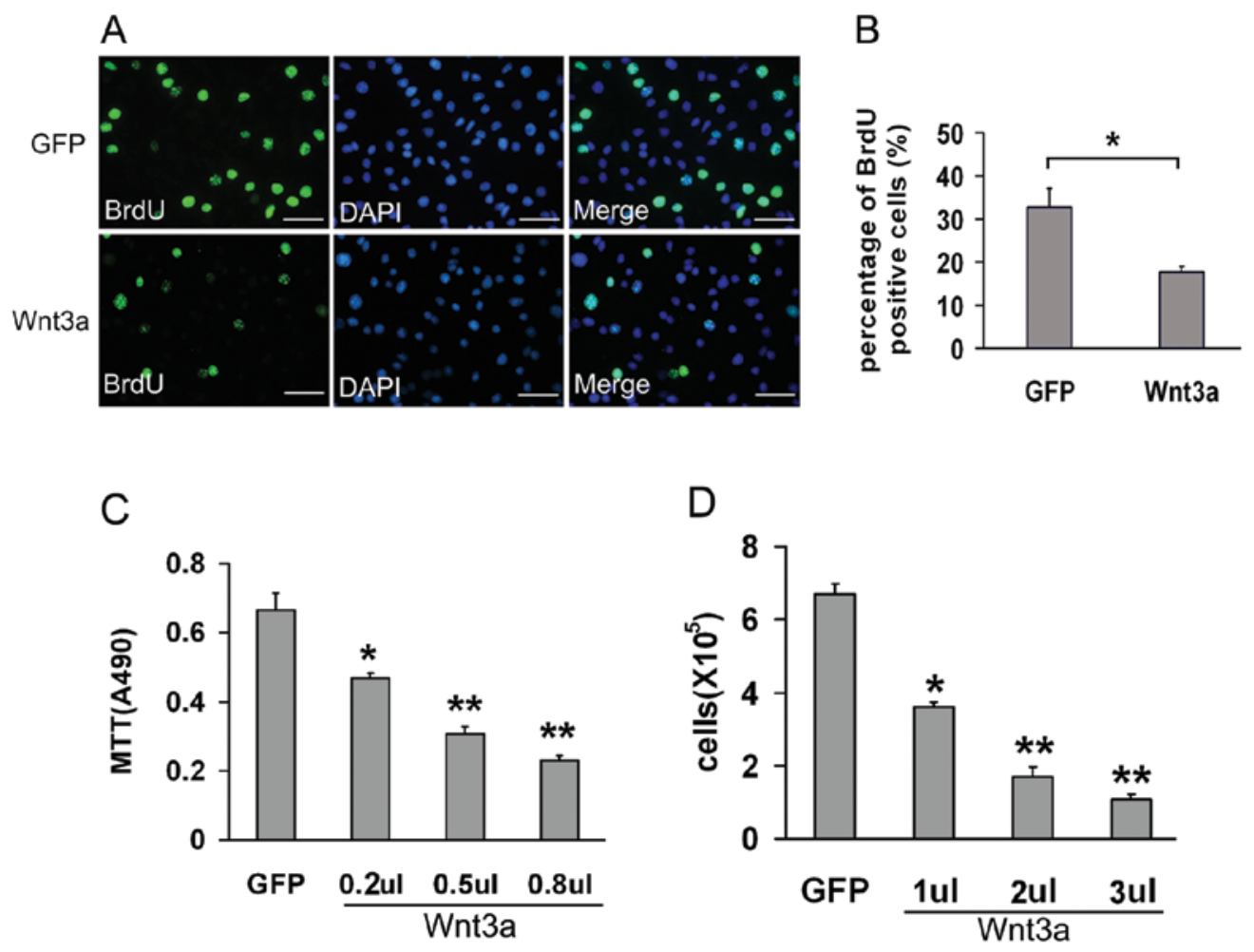

Figure 2. Effects of Wnt3a on melan-a cell proliferation. (A and B) BrdU incorporation in melan-a cells. (A) BrdU incorporation was detected in the nucleus after 3 days of AdWnt3a or AdGFP treatment, and (B) the percentages of BrdU positive cells were quantitatively measured. Green, BrdU; blue, DAPI. (C and D) Proliferation of melan-a cells infected with different doses of AdWnt3a or AdGFP as measured by (C) the MTT assay or (D) cytometry. Bars indicate the average and standard deviation of 3 biological replicates, and the data shown represent three experiments performed in parallel. ${ }^{*} \mathrm{P}<0.05,{ }^{* *} \mathrm{P}<0.01 . \mathrm{n}=3$. Scale bars, $50 \mu \mathrm{m}$.

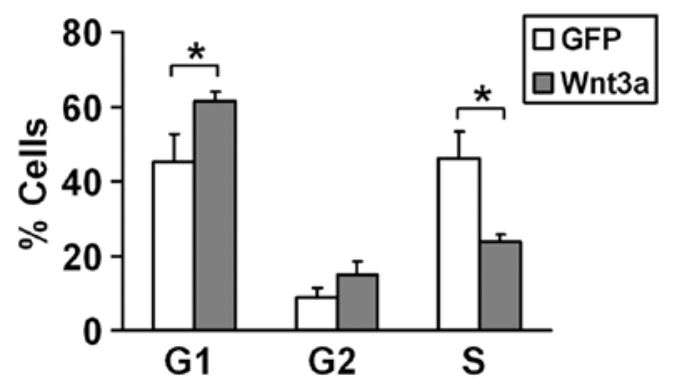

Figure 3. Effects of Wnt3a on cell cycle progression of melan-a cells. Cells treated with either AdWnt3a or AdGFP were harvested and analyzed by flow cytometry. AdWnt3a-infected cells decreased in the $\mathrm{S}$ phase and increased in the $\mathrm{G}_{1}$ phase compared to AdGFP-infected cells. ${ }^{*} \mathrm{P}<0.05$. $\mathrm{n}=3$.

analysis showed that the Wnt receptors Fzd1 to Fzd10 and the co-receptors LRP5 and LRP6 were all expressed in melan-a cells, indicating that melan-a cells could receive and transduce Wnt signals (Fig. 1E). We infected melan-a cells with AdWnt3a at a predetermined optimal titer. As observed in Fig. 1B, AdWnt3a mediated efficient gene transfer in melan-a cells. The expression of Wnt3a was confirmed by western blot analysis in AdWnt3a-infected cells but not in AdGFP-infected cells (Fig. 1C).

To evaluate the ability of AdWnt3a to activate Wnt/ $\beta$ catenin signaling, western blot analysis and the TOP/ FOP-flash luciferase reporter assay were performed. As shown in Fig. 1C, AdWnt3a upregulated the expression of $\beta$-catenin at the protein level. We infected melan-a cells with AdWnt3a or AdGFP and co-transfected with either the $\beta$-catenin responsive TCF4 reporter plasmid (TOP-flash) or with negative control reporter plasmids (FOP-flash). The luciferase activities showed that AdWnt3a-infected cells displayed higher ratios of TOP-flash/FOP-flash compared to AdGFP-infected cells (Fig. 1D). The data demonstrate that AdWnt3a efficiently activates Wnt/ $\beta$-catenin signaling in melan-a cells.

Wnt3a inhibits the proliferation of melan-a cells. To analyze the effect of Wnt3a on melan-a cell proliferation, we infected melan-a cells with different doses of AdWnt3a or AdGFP as control. After $72 \mathrm{~h}$, the MTT cell proliferation assay and manual cell count both showed that Wnt3a inhibited the proliferation of melan-a cell in a dose-dependent manner compared to GFP (Fig. 2C and D).

BrdU is a synthetic thymidine analog that gets incorporated into a DNA cell when the cell is dividing, so it is commonly used for the detection of proliferating cells. We measured the BrdU incorporation of AdWnt3a-infected melan-a cells and AdGFP-infected cells. The incorporated BrdU was detected by using the anti-BrdU antibody (Fig. 2A). The percentage of BrdU positive cells in AdWnt3a-infected cells was decreased by $14.9 \%$ (from $32.7 \pm 4.45$ to $17.8 \pm 1.32 \%, \mathrm{P}<0.05$ ) (Fig. $2 \mathrm{~B}$ ), which implied that Wnt3a inhibited the proliferation of melan-a cells.

We also performed cell cycle analysis and found that AdWnt3a-infected cells exhibited an increased population in the $G_{1}$ phase and a decreased population in the $S$ phase compared to AdGFP-infected cells (Fig. 3). 


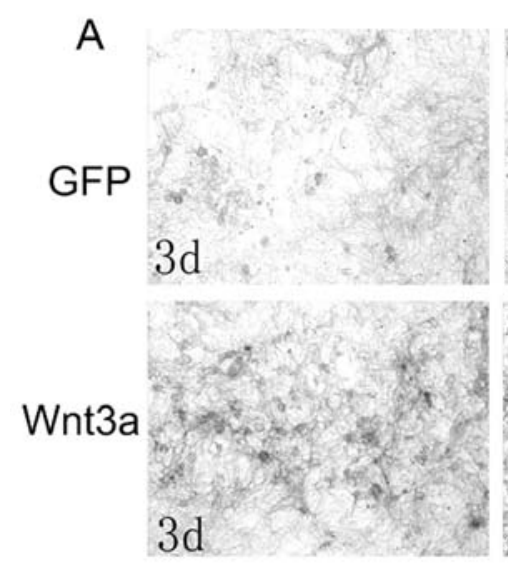

B

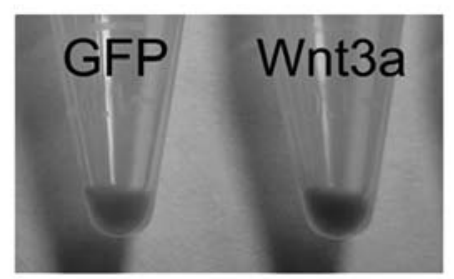

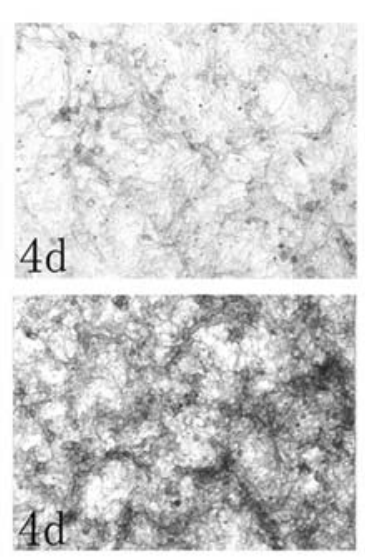
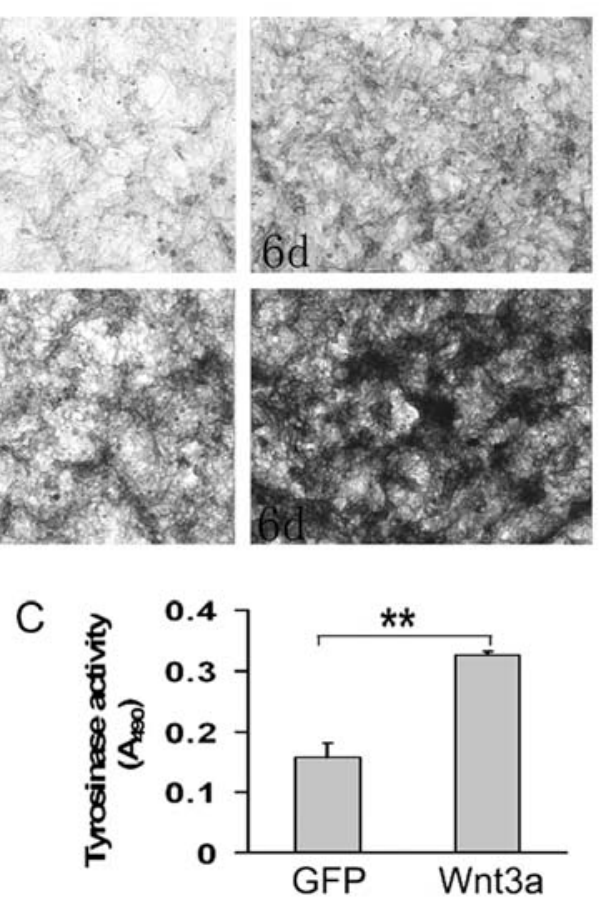

Figure 4. Effects of Wnt3a on pigmentation of melan-a cells. Melanin content of melan-a cells infected with AdWnt3a or AdGFP. (A) Melan-a cells were infected with AdWnt3a or AdGFP and the cells were shown by bright-field optics. Higher level of melanin accumulation in AdWnt3a-infected cells compared to AdGFP-infected cells. (B) Melan-a cells were seeded in 25- $\mathrm{cm}^{2}$ flasks and treated with AdWnt3a or AdGFP for 3 days, then collected and centrifuged to obtain cell pellets. Pigmentation of the pellets was photographed. (C) Tyrosinase activity of melan-a cells infected with AdWnt3a or AdGFP analyzed by the tyrosinase activity assay. These data are representative results of three independent experiments. ${ }^{* *} \mathrm{P}<0.01$.

A

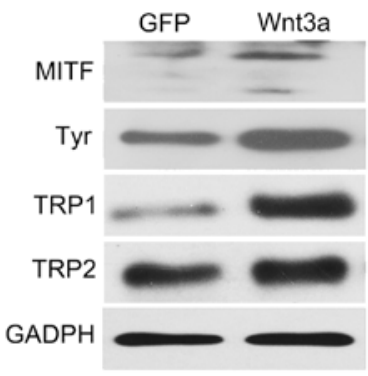

B

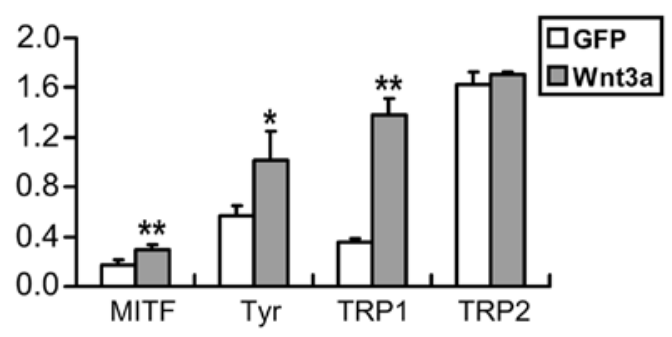

Figure 5. Effect of Wnt3a on the expression of the melanogenic enzymes in melan-a cells. (A) Melan-a cells were infected with AdGFP or AdWnt3a. After $72 \mathrm{~h}$, western blot analyses were performed with antibodies specific for MITF, tyrosinase, TRP1, TRP2 and GADPH as an internal control. (B) Relative protein expression levels. The data are representative results of three independent experiments. ${ }^{*} \mathrm{P}<0.05 ;{ }^{* *} \mathrm{P}<0.01$.

Taken together, these results showed that Wnt3a inhibited melan-a cell proliferation and this was associated with decreased population of cells in the $\mathrm{S}$ phase and an increase in the $\mathrm{G}_{1}$ phase.
Wnt3a promotes the melanogenesis of melan-a cells. We analyzed the effect of Wnt3a on the melanogenesis of melan-a cells by assessing melanin production and tyrosinase activity. Although almost all the cells contained melanin pigment, AdWnt3a-infected cells showed obvious higher level of melanin accumulation compared to AdGFP-infected cells (Fig. 4A and B).

To analyze whether melanin synthesis is activated via a direct effect on tyrosinase, tyrosinase activity assay was adopted to analyze tyrosinase activity in melan-a cells. As shown in Fig. 4C, a greatly significant increase of tyrosinase activity was detected in AdWnt3a-infected cells compared with AdGFP-infected cells.

To investigate how Wnt3a promotes melanin synthesis, we studied the expression of microphthalmia-associated transcription factor (MITF), the transcriptional master regulator of melanocytes, and its downstream target genes, including tyrosinase, TRP1, and TRP2 (25-27). Western blot analyses showed that Wnt3a significantly increased the expression levels of MITF, tyrosinase, and TRP1 in melan-a cells, but did not affect the expression of TRP2 (Fig. 5). Subsequently, we infected melan-a cells with AdSimMITF to knockdown the endogenous MITF. According to western blot analysis, the expression of MITF, and its downstream target genes, tyrosinase and TRP1, were dramatically decreased in the cells infected with AdSimMITF (Fig. 6). Co-infection of melan-a cells with AdSimMITF and AdWnt3a demonstrated that Wnt3a rescued the expression of MITF, tyrosinase and TRP1 (Fig. 6).

These results suggested that Wnt3a contributed to increase melanin synthesis through upregulation of the expression of MITF and its downstream genes, tyrosinase and TRP1. 


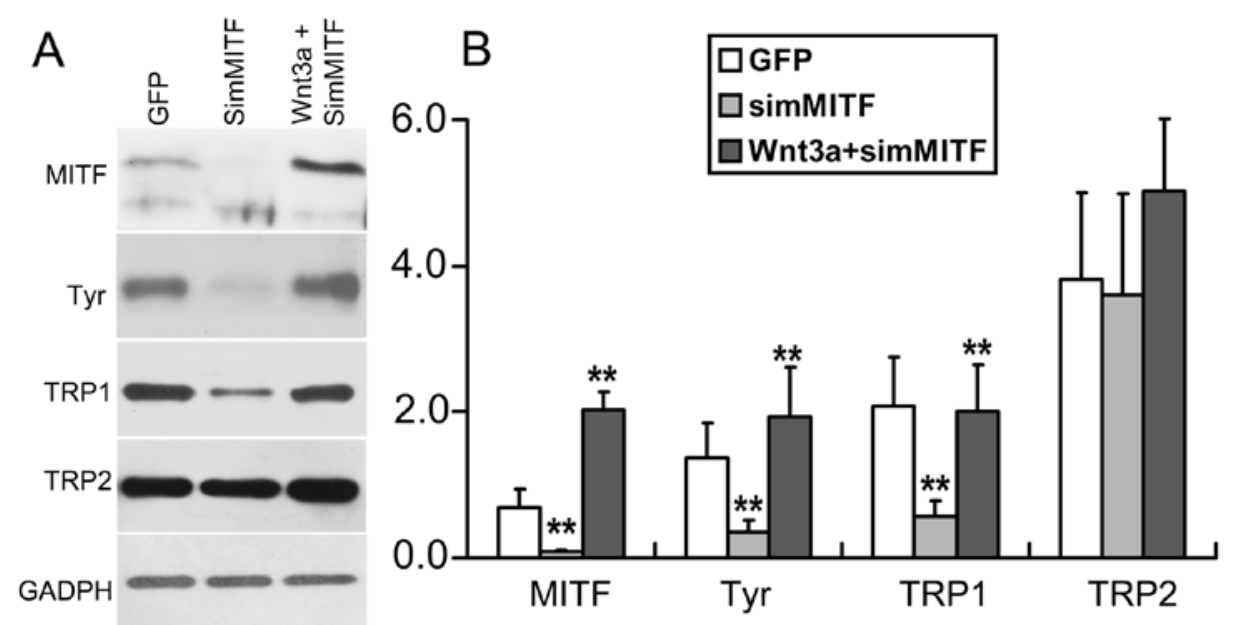

Figure 6. Effect of Wnt3a on the expression of the melanogenic enzymes in AdSimMITF-infected melan-a cells. (A) Melan-a cells were infected with AdGFP, AdSimMITF, or co-infected with AdSimMITF and AdWnt3a, respectively. After $72 \mathrm{~h}$, western blot analyses were performed with antibodies specific for MITF, tyrosinase, TRP1, TRP2 and GADPH. (B) The relative protein expression level. The data are representative results of three independent experiments. ${ }^{*} \mathrm{P}<0.05 ;{ }^{* *} \mathrm{P}<0.01$

\section{Discussion}

The Wnt signaling pathway is critical for regulating multiple aspects of basic cell functions, including proliferation, polarity, differentiation, and migration of cells (10-12). Despite the well-known role of Wnt3a in the development of melanocytes, the role of Wnt3a in mature melanocytes remains unknown. Therefore, this study was conducted to address this question.

The melan-a melanocytes were originally derived from normal epidermal melanoblasts from embryos of inbred C57BL/6J mice. When the cell line was established, the primary culture was unpigmented melanoblasts, which then matured to pigmented melanocytes in the incubation (21). We thus used melan-a as an in vitro cell model to investigate the effect of Wnt3a in mature melanocytes.

Wnt/ $\beta$-catenin signaling is mediated by binding to Frizzled (Fzd) receptors and low density lipoprotein-related protein (LRP)5/6, and induces various cellular events. Fzd1, Fzd3, Fzd8 and LRP6 have been demonstrated to act as receptors for Wnt3a (28-32). Our RT-PCR result showed that melan-a cells expressed Wnt receptors, Fzd (Fzd1-10), and the co-receptors LRP5 and LRP6, suggesting that melan-a cells could respond to Wnt3a. In this study, we infected melan-a cells with AdWnt3a and demonstrated that AdWnt3a expressed Wnt3a protein and efficiently activated $\mathrm{Wnt} / \beta$-catenin signaling in melan-a cells. Rabbani et al (33) co-cultured Wnt10btransfected epithelial cells with melan-a cells and found that Wnt10b secreted by epithelial cells could activate Wnt/ $\beta$ catenin signaling in melan-a cells. We treated melan-a cells with the conditioned medium from JB6 mouse keratinocytes infected with AdWnt3a for 2 days. Wnt/ $\beta$-catenin signaling in melan-a cells was also activated by testing TOP-flash system (data not shown). These results suggest that melan-a cells may respond to Wnt3a secreted by itself in an autocrine manner or secreted by keratinocytes in a paracrine manner in vitro.

Wnt signaling has been associated with proliferation of cells. Previous studies showed that Wnt3a promoted the proliferation of epidermal stem cells, mesenchymal stem cells, and fibroblast cells, and inhibited the proliferation of
B-ALL cell lines (33-37). As for the melanocyte cell lineage, Dunn et al (16) reported that Wnt3a did not stimulate proliferation of melanoblasts in vitro, and Delmas et al (38) reported that stabilized $\beta$-catenin reduced the number of melanoblasts in vivo. Similar to findings in melanoblasts, Wnt3a failed to induce and, in fact, inhibited mature melanocyte proliferation in this study. It is important to bear in mind that Wnt3a may play distinct roles in different cell types, developmental stages, and organismal origin.

In mammalian melanocytes, melanin biosynthesis is catalyzed by three melanocyte-specific enzymes: tyrosinase, tyrosinase-related protein-1 (TRP1) and TRP2 (6). Tyrosinase is the rate-limiting enzyme in melanogenesis while TRP1 and TRP2 function as downstream of enzymes in the melanin biosynthetic pathway. To investigate the influence of Wnt3a on melanogenesis of mouse melanocytes, we analyzed tyrosinase activity and melanin content in melan-a cells. The data showed that Wnt3a significantly increased tyrosinase activity and melanin synthesis in melan-a cells. In support of our findings, previous studies have reported that inhibition of Wnt/ $\beta$-catenin signaling strongly inhibited melanin synthesis $(20,39)$.

Melanin synthesis is stimulated by a large number of effectors, including cAMP-elevating agents, cholera toxin, UV light and so on. MITF is the master regulator of melanogenesis that regulates the expression of the melanogenic enzymes, tyrosinase, TRP1, and TRP2 as well as other pigmentation factors $(25,40)$. In this study, we detected the expression of MITF and its downstream target genes, tyrosinase, TRP1 and TRP2, and demonstrated that Wnt3a upregulated the expression of MITF, tyrosinase, and TRP1 in melan-a cells at the protein level. Furthermore, Wnt3a rescued the expression of MITF and its downstream target genes following reduction of endogenous MITF in melan-a cells by AdSimMITF. With the same melan-a cells, Takeda et al (41) found that Wnt3a protein induced MITF mRNA expression and activated the MITF promoter by recruiting LEF- 1 and $\beta$-catenin to the LEF-1-binding site. Our data were consistent with the result of Takeda et al (41) which demonstrated that MITF is a target gene of Wnt3a signaling. 
In conclusion, the study demonstrates that $\mathrm{Wnt} 3$ a reduces the proliferation of melan-a cells while simultaneously increases the melanin synthesis through the upregulation of MITF and its downstream genes, tyrosinase and TRP1.

\section{Acknowledgements}

This study was supported by the National Natural Science Foundation of China (no. 30872711). We thank Dr T.C. He (Chicago University) for the adenovirus production and technical assistance. We thank Professor Dorothy C. Bennett (University of London) and Dr Zhixiu Lin (Chinese University of Hong Kong) for providing melan-a cells and for helpful advice.

\section{References}

1. Yamaguchi $\mathrm{Y}$, Brenner $\mathrm{M}$ and Hearing VJ: The regulation of skin pigmentation. J Biol Chem 282: 27557-27561, 2007.

2. Slominski A, Wortsman J, Plonka PM, Schallreuter KU, Paus R and Tobin DJ: Hair follicle pigmentation. J Invest Dermatol 124: 13-21, 2005.

3. Uong A and Zon LI: Melanocytes in development and cancer. J Cell Physiol 222: 38-41, 2010.

4. White RM and Zon LI: Melanocytes in development, regeneration, and cancer. Cell Stem Cell 3: 242-252, 2008

5. Park HY, Kosmadaki M, Yaar M and Gilchrest BA: Cellular mechanisms regulating human melanogenesis. Cell Mol Life Sci 66: 1493-1506, 2009.

6. Slominski A, Tobin DJ, Shibahara S and Wortsman J: Melanin pigmentation in mammalian skin and its hormonal regulation. Physiol Rev 84: 1155-1228, 2004.

7. Cui J, Shen LY and Wang GC: Role of hair follicles in the repigmentation of vitiligo. J Invest Dermatol 97: 410-416, 1991.

8. Nishimura EK, Granter SR and Fisher DE: Mechanisms of hair graying: incomplete melanocyte stem cell maintenance in the niche. Science 307: 720-724, 2005.

9. Passeron T, Mantoux F and Ortonne JP: Genetic disorders of pigmentation. Clin Dermatol 23: 56-67, 2005.

10. Miller JR: The Wnts. Genome Biol 3: review 3001, 2002.

11. Eisenmann DM: Wnt signaling. WormBook: 1-17, 2005 (www. wormbook.org/toc_signaltrans.html).

12. Sethi JK and Vidal-Puig A: Wnt signalling and the control of cellular metabolism. Biochem J 427: 1-17, 2010.

13. Moon, RT, Brown JD and Torres M: WNTs modulate cell fate and behavior during vertebrate development. Trends Genet 13: 157-162, 1997

14. Dorsky RI, Moon RT and Raible DW: Control of neural crest cell fate by the Wnt signalling pathway. Nature 396: 370-373, 1998.

15. Dorsky RI, Moon RT and Raible DW: Neural crest-directed gene transfer demonstrates Wnt1 role in melanocyte expansion and differentiation during mouse development. Proc Natl Acad Sci USA 97: 10050-10055, 2000.

16. Dunn KJ, Brady M, Jambor CO, Snyder S, Incao A and Pavan WJ: WNT1 and WNT3a promote expansion of melanocytes through distinct modes of action. Pigment Cell Res 18: 167-180, 2005

17. Jin EJ, Erickson CA, Takada S and Burrus LW: Wnt and BMP signaling govern lineage segregation of melanocytes in the avian embryo. Dev Biol 233: 22-37, 2001.

18. Ikeya M, Lee SM, Johnson JE, McMahon AP and Takada S Wnt signalling required for expansion of neural crest and CNS progenitors. Nature 389: 966-970, 1997.

19. Yamaguchi Y, Itami S, Watabe H, et al: Mesenchymal-epithelial interactions in the skin: increased expression of dickkopf 1 by palmoplantar fibroblasts inhibits melanocyte growth and differentiation. J Cell Biol 165: 275-285, 2004.

20. Yamaguchi Y, Passeron T, Hoashi T, et al: Dickkopf 1 (DKK1) regulates skin pigmentation and thickness by affecting Wnt/ beta-catenin signaling in keratinocytes. FASEB J 22: 1009-1020, 2008 .
21. Bennett DC, Cooper PJ and Hart IR: A line of non-tumorigenic mouse melanocytes, syngeneic with the B16 melanoma and requiring a tumour promoter for growth. Int J Cancer 39: 414-418, 1987.

22. Luo J, Deng ZL, Luo X, et al: A protocol for rapid generation of recombinant adenoviruses using the AdEasy system. Nat Protoc 2: 1236-1247, 2007.

23. Peng Y, Kang Q, Cheng H, et al: Transcriptional characterization of bone morphogenetic proteins (BMPs)-mediated osteogenic signaling. J Cell Biochem 90: 1149-1165, 2003.

24. Nishimura EK, Suzuki M, Igras V, et al: Key roles for transforming growth factor beta in melanocyte stem cell maintenance. Cell Stem Cell 6: 130-140, 2010.

25. Widlund HR and Fisher DE: Microphthalamia-associated transcription factor: a critical regulator of pigment cell development and survival. Oncogene 22: 3035-3041, 2003.

26. Steingrimsson E, Copeland NG and Jenkins NA: Melanocytes and the microphthalmia transcription factor network. Annu Rev Genet 38: 365-411, 2004.

27. Shibahara S, Yasumoto K, Amae S, et al: Regulation of pigment cell-specific gene expression by MITF. Pigment Cell Res 13 (Suppl 8): S98-S102, 2000.

28. Chacon MA, Varela-Nallar L and Inestrosa NC: Frizzled-1 is involved in the neuroprotective effect of Wnt3a against Abeta oligomers. J Cell Physiol 217: 215-227, 2008.

29.Yamamoto H, Komekado $\mathrm{H}$ and Kikuchi A: Caveolin is necessary for Wnt-3a-dependent internalization of LRP6 and accumulation of beta-catenin. Dev Cell 11: 213-223, 2006.

30. Yamamoto H, Sakane H, Yamamoto H, Michiue T and Kikuchi A Wnt3a and Dkk1 regulate distinct internalization pathways of LRP6 to tune the activation of beta-catenin signaling. Dev Cell 5: 37-48, 2008.

31. Endo Y, Beauchamp E, Woods D, et al: Wnt-3a and Dickkopf-1 stimulate neurite outgrowth in Ewing tumor cells via a Frizzled3and c-Jun N-terminal kinase-dependent mechanism. Mol Cell Biol 28: 2368-2379, 2008.

32. Komekado H, Yamamoto H, Chiba T and Kikuchi A: Glycosylation and palmitoylation of Wnt-3a are coupled to produce an active form of Wnt-3a. Genes Cells 12: 521-534, 2007.

33. Rabbani P, Takeo M, Chou W, et al: Coordinated activation of wnt in epithelial and melanocyte stem cells initiates pigmented hair regeneration. Cell 145: 941-955, 2011.

34. Shang YC, Wang $\mathrm{SH}$, Xiong $\mathrm{F}$, et al: Wnt3a signaling promotes proliferation, myogenic differentiation, and migration of rat bone marrow mesenchymal stem cells. Acta Pharmacol Sin 28 1761-1774, 2007.

35. Jia L, Zhou J, Peng S, Li J, Cao Y and Duan E: Effects of Wnt3a on proliferation and differentiation of human epidermal stem cells. Biochem Biophys Res Commun 368: 483-488, 2008.

36. Boland GM, Perkins G, Hall DJ and Tuan RS: Wnt 3a promotes proliferation and suppresses osteogenic differentiation of adult human mesenchymal stem cells. J Cell Biochem 93: 1210-1230, 2004.

37. Nygren MK, Dosen G, Hystad ME, Stubberud H, Funderud S and Rian E: Wnt $3 \mathrm{~A}$ activates canonical Wnt signalling in acute lymphoblastic leukaemia (ALL) cells and inhibits the proliferation of B-ALL cell lines. Br J Haematol 136: 400-413, 2007.

38. Delmas V, Beermann F, Martinozzi S, et al: Beta-catenin induces immortalization of melanocytes by suppressing p16INK4a expression and cooperates with N-Ras in melanoma development. Genes Dev 21: 2923-2935, 2007.

39. Cho M, Ryu M, Jeong Y, et al: Cardamonin suppresses melanogenesis by inhibition of Wnt/beta-catenin signaling. Biochem Biophys Res Commun 390: 500-505, 2009.

40. Aksan I and Goding CR: Targeting the microphthalmia basic helix-loop-helix-leucine zipper transcription factor to a subset of E-box elements in vitro and in vivo. Mol Cell Biol 18: 6930-6938, 1998.

41. Takeda K, Yasumoto K, Takada R, et al: Induction of melanocyte-specific microphthalmia-associated transcription factor by Wnt-3a. J Biol Chem 275: 14013-14016, 2000. 